\title{
Correction to: Heredity and in vivo confocal microscopy \\ of punctiform and polychromatic pre-Descemet dystrophy
}

\author{
María Angélica Henríquez-Recine ${ }^{1}$ • Kelly Sonia Marquina-Lima ${ }^{1}$ • Elena Vallespín-García ${ }^{2}$ - Sixto García-Miñaur ${ }^{2}$. \\ José Manuel Benitez Del Castillo ${ }^{3}$. Ana Boto de los Bueis ${ }^{1}$
}

Published online: 4 March 2019

(C) Springer-Verlag GmbH Germany, part of Springer Nature 2019

\section{Correction to: Graefe's Archive for Clinical and Experimental Ophthalmology (2018) 256:1661-1667 \\ https://doi.org/10.1007/s00417-018-3993-x}

In the original publication, presentation of the following author names are incorrect in the HTML version. See below for the correction:

Henríquez-Recine, MA

Marquina-Lima, KS

Vallespín-García, E

García-Miñaur, S

Benítez Del Castillo, JM

Boto de los Bueis, A

Publisher's note Springer Nature remains neutral with regard to jurisdictional claims in published maps and institutional affiliations.

The online version of the original article can be found at https://doi.org/ $10.1007 / \mathrm{s} 00417-018-3993-\mathrm{x}$

María Angélica Henríquez-Recine

maria.angelica.h@gmail.com

1 Department of Ophthalmology, La Paz University Hospital, idiPaz, Sor Ángela de la Cruz road, number 9, 7A door, 28020 Madrid, Spain

2 Department of Genetics, La Paz University Hospital, idiPaz, Madrid, Spain

3 Department of Ophthalmology, San Carlos Clinic University Hospital, Madrid, Spain 